\title{
IMPLEMENTATION OF STATISTICAL PROCESS CONTROL (SPC) IN THE SEWING SECTION OF GARMENT INDUSTRY FOR QUALITY IMPROVEMENT
}

\author{
Mulat Alubel Abtew ${ }^{2,4}$, Subhalakshmi Kropi ${ }^{3}$, Yan Hong $^{4}$ and Linzi PU1 \\ ${ }^{1}$ School of Arts and Garment Engineering, Changshu Institute of Technology, Suzhou, 215021, Jiangsu, China, plz1986@sina.com \\ ${ }^{2}$ Ethiopian Institute of Textile and Fashion Technology (EiTEX), Lecturer, Bahir Dar University, Bahir Dar, Ethiopia \\ ${ }^{3}$ Department of Fashion Technology, National Institute of Fashion Technology (NIFT), Assistant Professor, Bangalore, India \\ ${ }^{4}$ University of Lille North of France, ENSAIT, GEMTEX, F-59100, Roubaix, France
}

\begin{abstract}
:
The main aim of this research was to implement appropriate Statistical Process Control (SPC) techniques for quality characteristics on sewing floor of garment Industry. Among different SPC quality improvements tools, control charts have been selected. After analyzing and selecting different critical parameters based on company and customer requirements, the $X$-bar and $R$ charts for variable and c-charts for attribute quality characteristics have been identified and implemented in the trouser sewing lines for quality improvement. The check points for selected control chart implementation have also been designed. Remedial action plans for the occurred special cause variations and process stability were developed. The project incorporated theoretical and on-job training schemes for different quality team members, to understand the SPC concept and its implementation procedure. After implementation, significant improvements in the sewing section were achieved. The four months analysis before and after implementation of the SPC tools showed that the rejection percentage was reduced from $9.141 \%$ to $6.4 \%$. Successful implementation of the result of this project can significantly improve process performance of other similar manufacturing units with appropriate modification.
\end{abstract}

\section{Keywords:}

Statistical Process Control (SPC); quality improvement; garment sewing line.

\section{Introduction}

Total quality management (TQM) is a people focused management system that aims at continual improvement in customer satisfaction. According to Mason B. and Antony J., Statistical Process Control (SPC) is a technique used within the TQM framework for reducing variation in processes that we deal with everyday [1]. It is a powerful technique to control, manage, analyze and improve the performance of a process by eliminating special causes of variation in processes such as tool wear, operator error, errors in measurements, use of improper raw materials, and so on. Reference[2] is also defined as a powerful collection of problem-solving tools useful in achieving process stability and improving capability through education on variability. It is also a technique developed based on Shewhart's conception of process variability, which is widely applied not only in manufacturing processes but also in service operations. In order to survive in a competitive market, improving quality and productivity of products is a must for any company. SPC techniques have been widely recognized as effective approaches for process monitoring and diagnosis. It provides use of the statistical principals and techniques at every stage of the production. SPC aims to control quality characteristics on the methods, machine, products and equipment, both for the company and operators with the magnificent seven.

There are two kinds of variations that occur in all manufacturing processes, which cause subsequent variations in the final product. The first is known as the common cause of variation and consists of the variation inherent in the process as it is designed. It may include variations in temperature, properties of raw materials, strength of an electrical volt and so on. The second kind of variation is known as a special cause of variation and happens less frequently than the first. Since checking quality of a product in the sewing section using $100 \%$ inspection is time consuming and expensive, in this paper, the authors have great interest in implementing appropriate SPC tools in the sewing section of Silver Spark Apparel Limited, to enhance process performance for quality products.

Generally, there are three different ways of SPC tool implementation.

1. SPC software: Its advantage is that it is user friendly, easy to understand, easier storage and retrieval of data. It has disadvantages like operator errors in the data entries, inability to construct pie or bar charts and operator delays in entering data into the system.

2. SPC in Excel sheet: It is simple, easy to understand and provides a basic graphic facility. Its disadvantage includes operator errors in data entries, inability to support multiple users, and feature to signal workers, if an out-of-specification value occurs.

3. SPC with manual application: It involves manual plotting of data on control charts using graph paper. Advantages of these systems are simple and very good when implemented for the 
first time. However, these are subject to certain limitations, when applied to industrial sectors with few quality fault occurrences when implementing for the first time.

\subsection{Introduction to Basic SPC Tools}

As shown in Figure 1, there are seven quality tools available to improve processes.

i. Pareto Chart: It can be used to display categories of problems graphically, so that they can be properly prioritized.

ii. Cause-and-Effect Sheet: It organizes and displays the relationships between different causes for the effect that is being examined and helps to organize the brainstorming process.

iii. Scatter Diagram: It is used to uncover possible cause-andeffect relationships.

iv. Flow Chart: It is a type of diagram that represents an algorithm, workflow or process, showing the steps as boxes of various kinds, and their order by connecting them with arrows.

v. Histogram: It is a snapshot of the variation of a product or the results of a process.

vi. Check sheets: These are simply charts for gathering data. When check sheets are designed clearly and cleanly, they assist in gathering accurate and pertinent data, and allow the data to be easily read and used.

vii. Control Charts: These are graphical devices that aid in process control and make it easy to identify points and processes that are out of control, without using complicated statistical tests.

\subsection{Introduction to Garment Manufacturing}

The garment manufacturing industry is a large and most export-oriented field in developing countries in terms of output, export and employment creations. Manufacturing costs of garment products partially depend on quality inspection costs. The survival against competition in terms of manufacturing cost versus selling price is increasing day by day in the competitive global market. Since sewing lines are labor intensive fields, there is little chance for improvement by technological changes, but there are vast scopes of improvement of these areas by applying various scientific approaches. It is noted that according to lean manufacturing, quality inspection is a necessary but non value added activity that needs reduction. It may be possible to reduce these non value added activities from the manufacturing processes by applying statistical quality control systems. Nowadays, the apparel manufacturing industries are trying to develop their current production system and are continuously looking for new implementation tools in order to maintain swiftness with the rapid changes of trends of apparel products amongst the consumers. There is no doubt that sewing section is the most momentous and teeming department that plays a vital role in the apparel industry. To improve the existing situation and to increase effectiveness of the inspection process, the implementation of SPC techniques is a very important step.

\subsection{Company Background}

Silver Spark Apparel Limited (SSAL), A Raymond Group Company: Incorporated in 1925, the Raymond Group is a Rs. 14,000 million plus conglomerate having businesses in Textiles, Readymade Garments, Engineering Files and Tools, Prophylactics and Toiletries. The group is the leader in textiles, apparel and files and tools in India and enjoys a pronounced position in the international market. Raymond is considered a pioneer in the development of the woolen and worsted textiles market in India. A strong heritage of in-house research and development, a range of over 20,000 shades and designs, more than 4000 multi-brand outlets and over 281 exclusive retail shops makes Raymond the largest and most respected textile brand in India. Silver Spark Apparel Limited (SSAL) is well known for producing jackets, suits and formal trousers, with high quality and technologically advanced machines. It is a part of an 80-year-old leading business group in the garment industry, Raymond India Ltd. The specialty of the plant is the superior manufacturing of the jackets that are in line with

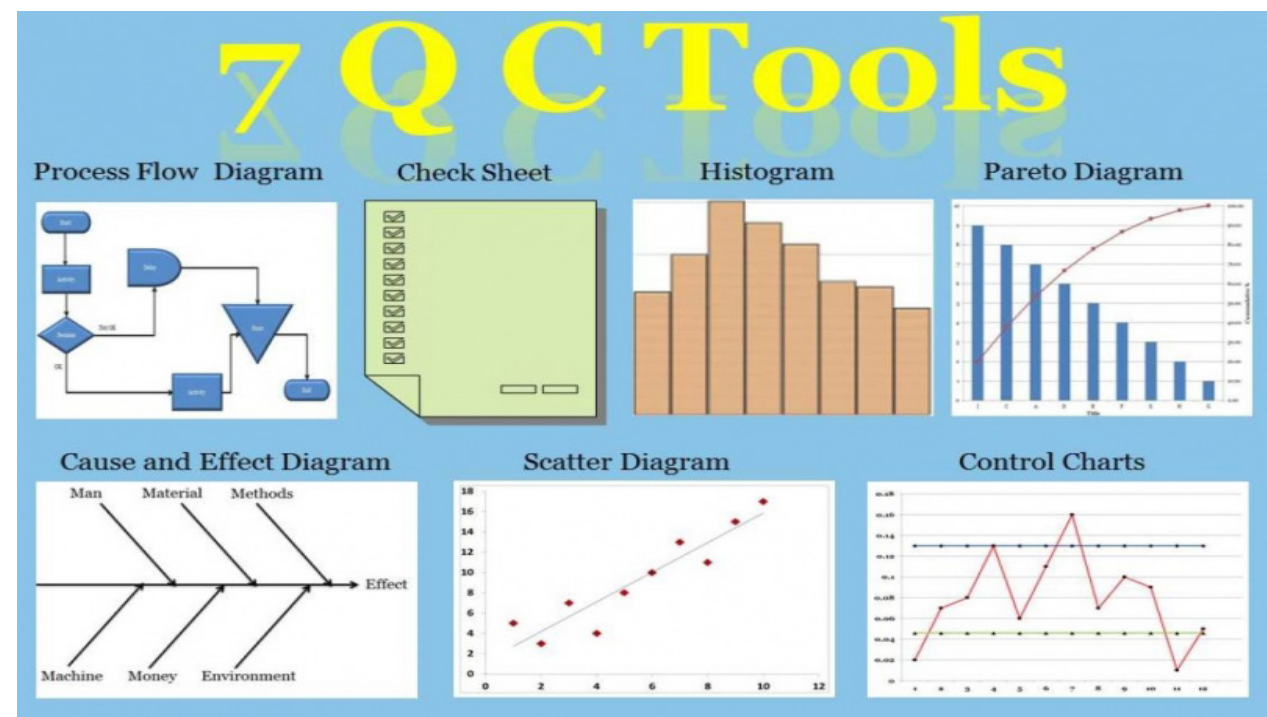

Figure 1. The seven SPC tools 
Italian and Japanese quality levels, which are known for best quality jackets in the world. It exports $85 \%$ of its production. Its clientele includes: Calvin Klein, Levi's, Konaka, Jet Airways, Qatar Airways, Park Avenue, GAP and others.

The objective of this research project is to implement SPC in the sewing section of trouser lines at SSAL Company, for process performance improvement. The project is structurally organized as follows: Chapter 2 will be on review of relevant literature. Chapter 3 will cover methodology, to determine the critical parameters and appropriate tools for SPC implementation. Chapter 4 will be on data analysis and implementation of SPC, while chapter 5 will be on measurement and explanation of implementation results. Chapter 6 will be on summaries and conclusions followed by the last chapter on suggestion for future improvement.

\section{Literature Review}

SPC was pioneered by W. A. Shewhart in the early 1920s. In 1939 , he created the basis for the control chart and the concept of a state of statistical control, through carefully designed experiments.[3] He discovered that some process variation in manufacturing data is natural to the process, while others display uncontrolled variation that is not present in the process causal system. W. E. Deming later applied SPC methods in the US during the World War II, thereby, successfully improving the quality in the manufacturing of munitions and other strategically important products. Deming also introduced SPC methods to Japanese industries after the war. The methods were practiced by many manufacturing and service organizations. Sultana $F$. et al.[4] tried to show machine breakdown frequencies and time duration of making cigarettes, as well as the major causes of those breakdowns by using SPC. Semel F. J. et al.[5] indicated implications, not only to manufacturing and quality but also to research programs and product development.

Hikmat et al.[6] focused on monitoring real life data in a Jordanian manufacturing company that specialized in producing steel to identify the key ingredients for successful quality management in any organization. The research attempted to show the intergradations between SPC tools and effective implementation of SPC. Another investigation was by Ab Rahman M. N. et al.[7] that studied eight companies, only four of them fully implemented the SPC system. Their study compared the companies' level of SPC adoption, types of SPC software used, problems encountered and advantages of its application. Ab Rahman M. $\mathrm{N}$ et al.[8] carried out a case study on the implementation of SPC in eight Malaysian manufacturing companies using different methodologies. Finison et al.[9] discussed the fundamental control chart theory in the context of implementing SPC charts in healthcare applications, while Phillips R.W.[10] explained that statistical analysis is necessary when variation exists. Stephanie J.R. et al.[11] demonstrated that SPC charts are very useful in monitoring survey data quality.

Sharaf El-Din M.A. et al.[12] reported that after analyzing and monitoring the process of steam generation in steel making, some problems were sorted out by using conventional univariate control charts and a single multivariate control chart. Omar M. $H .[13]$ indicated that the main aim in using the SPC charts is to increase consistency wherever possible and to decrease inconsistencies when they happen without unnecessary cost of slowing the mass rating process. According to Victor E. S., Jaideep G. M., and Michael J. S.,[14] the $\delta$ chart is an effective technique in addressing the limitations of $X$ charts for short production runs. In conjunction with standard range charts, $\delta$ charts can provide effective means to monitor and control processes, which might otherwise be deemed unsuitable for SPC control charting. Brannstrom-Stenberg and Deleryd[15] concluded in their research that organizations that have implemented SPC of their own free will, experience advantages to a greater extent.

Kuang-Han Chen et al.[16] noted their introduction of a new eigen space detection strategy, to detect subtle covariance structure change. According to Hanna S. M.,[17] SPC is routinely used to monitor different accelerator manufacturing processes, in which, the resulting data is used to initiate actions to preserve consistent and high-quality performance. Bakker A. et al.[18] reported their work on the characterization of statistical inference at work, to compare SPC as a commonly used technique for process improvement in industries with hypothesis testing. Anna L.S. and Sohail S. C.[19] noted on their study, the application SPC tools in public transportation services in the Philadelphia area, in the operation and maintenance of a large number of transit vehicles for daily use. Rungasamy, S., et al.[20] reported their work on the examination and analysis of implementation of SPC by conducting a survey of 33 manufacturing small and medium enterprises (SMEs). According to their research results, management commitment, process prioritization, control charting, teamwork and measurement system evaluation became critical success factors for successful implementation of SPC.

According to Raymond W. Phillips,[21] the use of analytic statistical analysis versus enumerative statistical analysis for valuating data from experiments and product studies. And also, he tried to generate data to acquire knowledge; analytical studies are conducted with the aim of prediction. Mitra A.,[22] defines quality, describes the history of the quality control movement, and discusses various aspects of management philosophies for quality improvement. Beamon and Ware[23] propose a framework that provides a methodology to implement a quality system for a supply chain process. Wood[24] proposes SPC chart guidelines in service processes. Does et al.[25] also note the need for commitment of top management before the initiation of an SPC project.

\section{Methodology}

This chapter describes the methodology of the research project. Basically, the implementation of SPC system was the main essence of this study. In order to achieve this objective, the existing sewing section processes, especially trouser lines, were first critically observed, studied and analyzed with regard to quality aspects using the operation breakdown of product lines, observing machines, methods and techniques used in 
the lines and studying the types of existing inspection methods. Later, after analyzing the processes, defects found in the lines were classified and studied, with their critical parameter. The location of the control charts' inspection checks points in the selected trouser lines were determined.

After studying two defects with their critical parameters and designing the check point, an appropriate SPC control chart for both variable and attribute quality parameters based on various dimensions were implemented. Considering the factory situation and analyzing the advantages and disadvantages of different methods of SPC implementation, it was noted that implementing the manual SPC methods became much more appropriate. This system mostly involved the plotting of data on control charts manually, using the prepared graph paper. The advantages of these systems were very simple and good when implemented for the first time. This system has certain advantages when applied in industrial sectors, where various quality faults occur.

Delivering offline and on-the-job training for quality checkers and supervisors has to be carried out for proper implementation of SPC and error reduction. After plotting the selected control chart separately for variable and attribute parameters, the data pattern was checked by run tests to justify the randomness properties of the collected data, within the lower and upper control limit. Immediate and permanent action plan was devised and maintained for special variation.

\section{Data Analysis and SPC Tool Implementation}

Since SSAL produced only formal trousers and jackets, the project mainly aimed to implement the SPC tools only for one formal trouser sewing line having two pleats at the front and one dart on the back. The company had five trouser lines and four jacket lines, as indicated in Table 1. The research started by collecting all relevant data consistently in the specified line.

As shown in Table 1 and Table 2, the operation breakdown of all trouser lines had three phases, with $80-90$ operations. Trouser line number 2 was selected for pilot purposes and different parameters affecting the processes were studied.

The company's sewing section used inline check point, random checking and end line checking (100\%) rather than other process improvement quality tools. This traditional process, particularly in stitching section, was used to generate a datum point, which was compared to a standard. If the point was out of specification, then action was taken on the product only. However, in order to substitute the traditional process by SPC, this project tried to develop and implement leadership, expert knowledge, education and training, plus the implementation plan in the company.

\subsection{Quality Characteristics in Sewing Section}

Quality characteristics are one or more elements that define

Table 1. SSAL Trouser and Jacket Sewing Lines, Production Capacity and Their Operation

\begin{tabular}{|c|c|c|c|c|}
\hline \multirow{2}{*}{ Sewing Lines } & \multicolumn{2}{|c|}{ Production Capacity } & \multicolumn{2}{c|}{ Number of Operations } \\
\cline { 2 - 5 } & Jacket & Trouser & Jacket & Trouser \\
\hline Line-1 & 350 per day & 550 per day & 120 & 80 \\
\hline Line-2 & 550 per day & 950 per day & 220 & 87 \\
\hline Line-3 & 350 per day & 550 per day & 120 & 88 \\
\hline Line-4 & 350 per day & 700 per day & 120 & 87 \\
\hline Line -5 & - & 550 per day & - & 87 \\
\hline
\end{tabular}

Table 2. Overall Operation of the Selected Trouser Line (Line 2)

\begin{tabular}{|c|c|c|c|}
\hline S.NO & Section & Operation & Phases \\
\hline 1 & Front Panel & 04 & \multirow{2}{*}{ Preparation Phase } \\
\hline 2 & Back Panel & 08 & \\
\hline 3 & Pocket Bag (Front) & 05 & \multirow{2}{*}{ Front and Back Phase } \\
\hline 4 & Fly & 02 & Assembly Phase \\
\hline 5 & Back Pocket & 05 & 13 \\
\hline 6 & Waist Band & 05 & \\
\hline 9 & Front and Back & 38 & 87 \\
\hline
\end{tabular}


the intended quality level of a product. In most manufacturing companies, including garment industry, quality characteristics are categorized into variable and attribute characteristics.

1) Variable quality characteristics: Quality characteristics that are measurable and are expressed on numerical scale are called variable. The circumference of waist, waist band height, inseam, out seam, leg opening, back rise, front rise, hip position and so on, which are expressed in inches, are examples of variable characteristics in the trousers.

2) Attribute quality characteristics: Quality characteristics that cannot be measured or expressed on a numerical scale are called attribute characteristics. They are mostly expressed as Good/ Bad, Acceptable/Rejected, Passed/Failed. A quality characteristic is said to be an attribute if it is classified as conforming (is a quality characteristic that does not meet its stipulated specification. Some of the examples of nonconformity in formal trousers are bar tack missing, side seam puckering, front placket open, label missed, back rise bend, waist band puckering) or nonconforming (these are garment pieces having one or more defects).

\subsection{Implementation of SPC Tools in the Selected Trouser Lines}

1) Designing and facilitating different working conditions for implementation: Setting up of SPC is not an easy task for the garment manufacturing. The implementation of the SPC for quality parameter passes different steps. When the intention is to implement quality tools, it is very critical to design and facilitate different working conditions prior to implementation.

a) Choosing critical quality characteristics of a process: During implementation, the selection of specific critical parameters for both variable and attribute is critical. The selection may be either a company's need for a quality improvement of the final product or the requirements of the customer. At this point, the critical parameters of the process control were applied and determined. Choosing carelessly of too many critical parameters causes loss of time, energy and may even result in the project ending without achieving a solution. Past experiences from different manufacturing units suggest that ten or less parameters per process are a good number.

In the company selection of the variables, the parameter for measurement was based on the requirements of buyers.
Some buyers were strict on some particular measurements than others. If the buyer gave lots of variable measurements, those quality characteristics were selected that caused more nonconforming items and increased the. Since the selected trouser line had more than 80 operations (Table 2), it was difficult to make a control chart for each and every process. The selected processes were also those that ran continuously, irrespective of products and checking of processes stability.

As shown in Figure 2, the alteration of trouser in four months (namely, November, December, January and February, 2009/2010) in the sewing line was analyzed to determine the critical process that brought more defects and affected attribute quality characteristics

The analysis in Figure 2 showed that different sewing processes caused different defects. According to the four months' data analysis, the average total alteration rate was approximately $9.141 \%$. Figure 3 also indicates the contribution of each process for the alteration rate. Based on this analysis, the selected attribute critical parameter was contributing $63.8 \%$ of alterations. Considering all the factors, eight critical parameters for both variable and attributes were identified, as shown in Table 3 .

b) Choice of appropriate check points where control charts were applied: The selection of check points was one of the things considered while implementing SPC. As shown in Figure 5 and 6 , this was strategic point, assigned by considering different parameters such as reduction of more defects, control of non-conformances, end of section and absence of a bottle neck in the line. Table 4 shows the selected three check point locations for the application of control charts in the specified trouser lines.

On the other hand, it was decided which control chart was to be used for attribute whether to control a single process, multiple processes or a number of products. This choice was influenced by the number of potential processes and products produced, costs incurred and the time required for inspection.

c) Selection of rational subgroup (sample): The principle of sampling states that the variation between subgroups should be solely attributable to the common causes in the system rather than the sampling method. In this research project, subgroups are chosen from the output of a short period to determine the

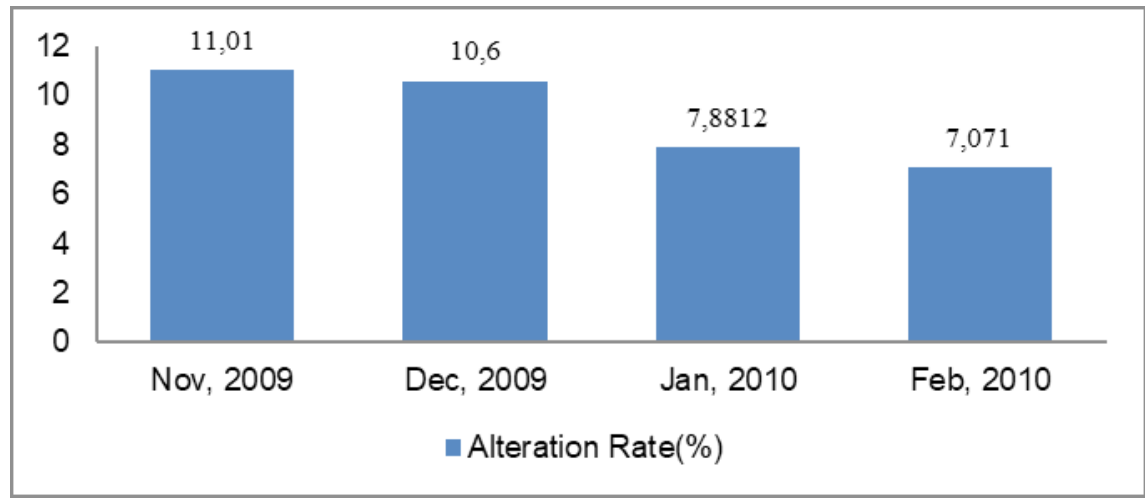

Figure 2. Average alteration rate percentages of the sewing line in four months before implementation 


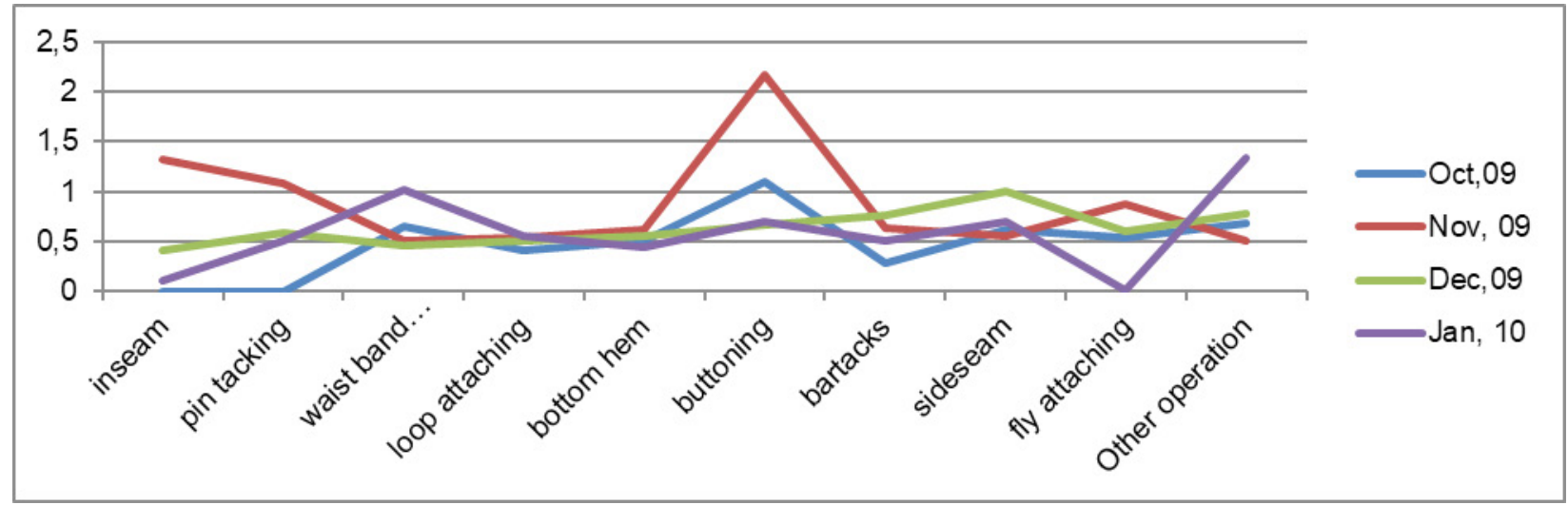

Figure 3. Process wise different alteration rate percentages of the sewing line in four months before implementation

Table 3. Critical Parameters for Variable and Attribute Characteristics for Konaka Buyer

\begin{tabular}{|c|c|c|}
\hline No. & Critical Parameter for variable & Critical Parameter for attribute \\
\hline 1 & Waist Measurement & Button attaching \\
\hline 2 & Hip measurement & Side seam \\
\hline 3 & Seat measurement & Inseam \\
\hline 4 & Thigh measurement & Waistband attaching \\
\hline 5 & Knee measurement & Back rise attaching \\
\hline 6 & Rise measurement & Looping \\
\hline 7 & Inseam /side seam measurement & Bar tack \\
\hline 8 & Bottom hem measurement & \\
\hline
\end{tabular}

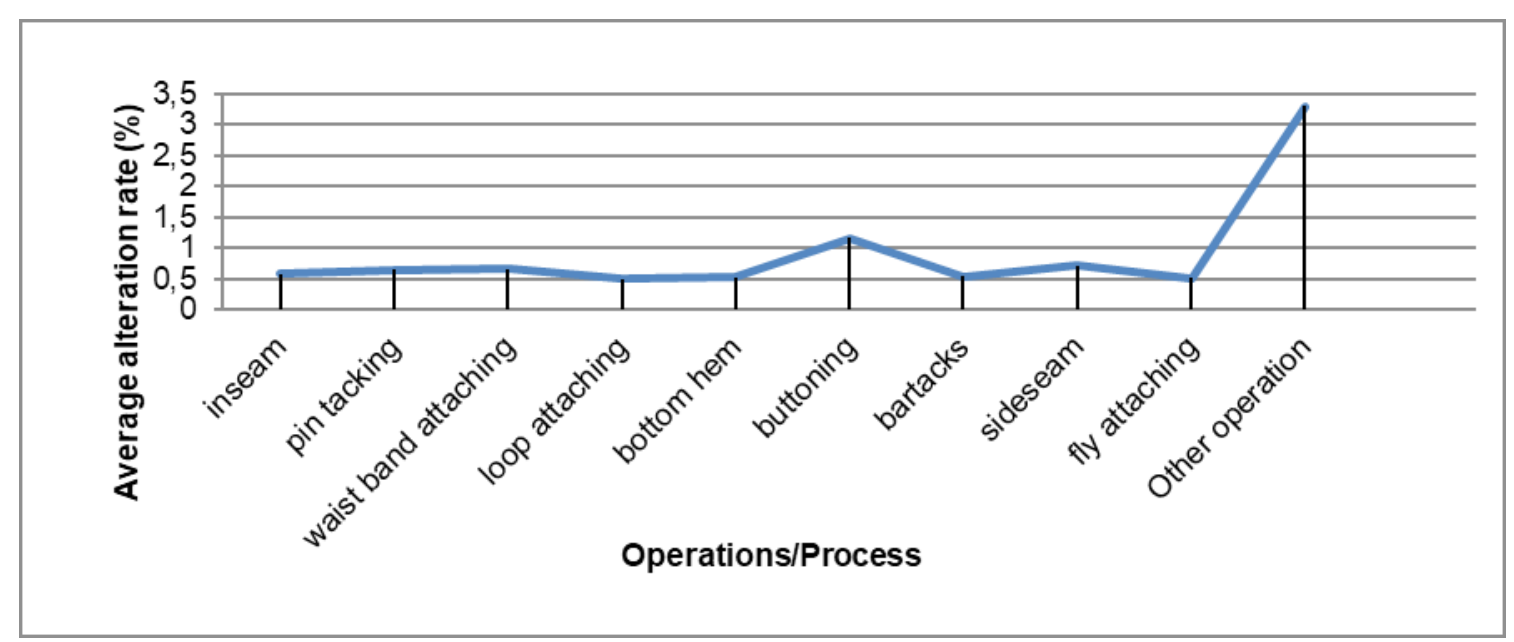

Figure 4. Average alteration rate percentages of the sewing line in four months before implementation

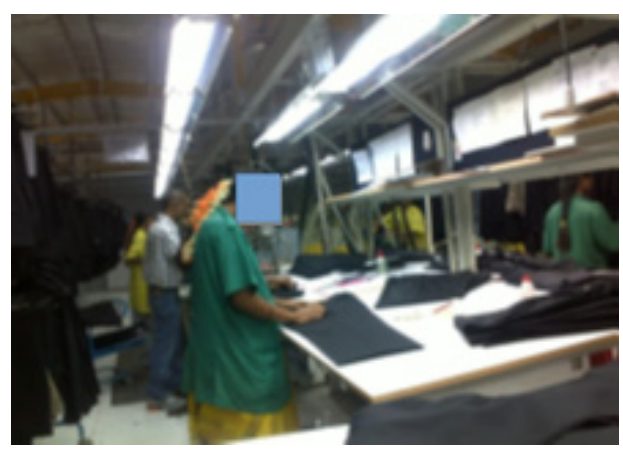

Figure 5. End line check point for attribute chart

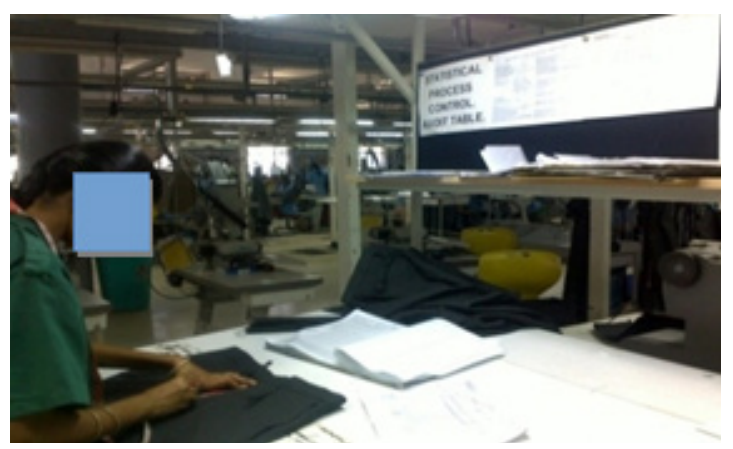

Figure 6. Inline check point for variable chart 
Table 4. Designed Check Points for Variable and Attribute

\begin{tabular}{|c|c|c|}
\hline & Designed check point for variable & Designed check point for Attribute \\
\hline i) & Front and Back check point & Preparatory Section check point \\
\hline 1 & Thigh \& Knee Measurement & Front serging \& Back serging \\
\hline 2 & Back pocket height & Front and Back check point \\
\hline 3 & Back pocket opening & Pleat making \\
\hline ii) & Inline check point & Fly attaching \\
\hline 1 & Waist measurement & Front pocket locking \& attaching \\
\hline 2 & Seat and Knee & Dart making and Back welting \\
\hline 3 & Front rise and back rise & Button hole and Buttoning \\
\hline 4 & Hip position & Assembly section check point \\
\hline 5 & Front pocket opening & Side seam and Inseam \\
\hline 6 & Thigh Measurement & Loop attaching and finishing \\
\hline 7 & Back pocket height & Waistband attaching \\
\hline iii) & End line check point & Front and Back rise \\
\hline 1 & Bottom hem & Extension button \\
\hline 2 & Loop length and width & Button Heming \& Label attaching \\
\hline 3 & Inseam and out seams & \\
\hline
\end{tabular}

variation in manufactured products close to each other in time sequence in order to be much more likely to represent chance variation. The variation represented within each subgroup is small so as to be feasible for the process, in order for any changes in the process to appear as differences between subgroups. The selected samples consist of garments that are produced in the same lines, coming from same batches, produced by same operators, made of the same fabric and having the same style.

d) Frequency and sizes of subgroups (samples): In most cases, the frequency depends upon the cost of obtaining information compared to the cost of detecting a nonconforming item and the degree of control achieved in the process. In the beginning, it may be necessary to increase the frequencies. However, once the process is controlled, it can be reduced. In this project, the frequency has been decided to be one hour for both variable and attribute. Sizes of subgroups depend on production rate, time taken to inspect, nature of inspecting the garment and cost of inspection. It is quite common in manufacturing industries to have a sample size of 4 or 5 . Considering the foregoing, all factors and size of subgroups for variable are consecutive and uniform, that is, five garment pieces each in the three checking points for every hour.

The accuracy as well as the similarity of measuring the instruments directly influence the quality of data collected. Variable measurement instruments should be well calibrated, standardized, uniform throughout the sample and have clearly visible bars or numbers.. Low quality data leads to erroneous conclusions. For proper calibration, a format has been developed and the tapes are checked and calibrated every two weeks with the standard scale. For attribute, acceptance sampling has been applied, to accept or reject products based on a random sample of the product, and its advantage is to sentence lots (accept or reject) rather than to estimate the quality of a lot. The sampling plan has been determined using the standards of Acceptance Quality Level 2.5 (AQL 2.5.), as shown in Table 5 . Since the specified company wants to achieve AQL 2.5, in the end, the same must be achieved in the sewing lines.

Table 5. AQL2.5 and the Sampling Plan for Lot Size 100 Trousers/hr

\begin{tabular}{|l|c|}
\hline $\begin{array}{l}\text { Population size (manufacturing } \\
\text { trouser/hr) }\end{array}$ & 100 -120 garment \\
\hline Quality Level & AQL 2.5 garments \\
\hline Sample size & 1and 2 respectively \\
\hline $\begin{array}{l}\text { Acceptance number and Rejection } \\
\text { units }\end{array}$ & \\
\hline
\end{tabular}

e) Determinations of appropriate control chart: After analyzing the different types of processes, sample sizes used and characteristics of the products in the production line, with the properties of different variables and attributes control charts, the type of control charts used were established. In garment industries, the mean value of the quality characteristics, as well as its variability, has to be controlled. The mean gives an indication of the central tendency of the process, and variability 
provides an idea of the process variation. Considering all those points among various charts, $\mathrm{X}-\mathrm{Bar}$ and $\mathrm{R}$ chart were found more appropriate for controlling variable processes, which is shown in Table 6 and 7 . Though the steps that followed were more or less the same, selecting an appropriate control chart for attribute was a little bit difficult due to different reasons. Since the sample size was constant (20 garments) and the fact that the number of defects should be controlled rather than defectives, it was found that the $\mathrm{C}$-chart was more appropriate for attribute in the sewing lines.

i) Construction and interpretation of control chart: The most difficult part of the implementation was determining and interpreting the special causes and selecting the remedial actions. Effective use of control charts requires operators who are familiar not only with the statistical foundation but also the process itself.

ii) Construction of the chart: There were three horizontal lines in the control chart, which is shown in Figure 7. The central line, which represented the average value of the characteristics being plotted and the two limits, that is, the upper and lower control limits used to make decisions.

Control chart for variable quality characteristics:

\section{A. For Median Average Chart}

$$
\mathrm{UCL}=\mathrm{x}+\mathrm{A} 2 \mathrm{R} L C L=\mathrm{x}-\mathrm{A} 2 \mathrm{R}
$$

Centre line $(x)=$ Average of median and $\mathrm{R}=$ Average range

Value of $A 2$ is different since it is a different sample size, that is, for $\mathrm{N}=5, \mathrm{~A} 2=0.577$.

\section{B. For Range chart}

$$
U C L=D 4 R L C L=D 3 R
$$

Central line $(x)=$ Average of range and $R=$ Average of range

Value of D3 and D4 is different since it is a different sample size, that is, for $\mathrm{N}=5, \mathrm{D} 3=0, \mathrm{D} 4=2.11$.

For attribute quality characteristics:
Table 6. Different Variable Charts with Different Variables

\begin{tabular}{|c|c|}
\hline Sample Size & Variable chart used \\
\hline If sample size=1 & IR and/or MR charts \\
\hline If sample size=2 & X-bar and/or X-bar/R charts \\
\hline If sample size=3 & X-bar and/or X-bar/X charts \\
\hline
\end{tabular}

Table 7. Different Attribute Charts with Different Variables

\begin{tabular}{|c|c|c|}
\hline & Defects & Defectives \\
\hline Variable Sample Size & U-Chart & P-Chart \\
\hline $\begin{array}{c}\text { Constant Sample } \\
\text { Size }\end{array}$ & C-Chart & NP-Chart \\
\hline
\end{tabular}

\section{A. For C-chart}

$$
\begin{aligned}
& U C L=c+3 \sigma c \& L C L=c-3 \sigma c \\
& \sigma c=\sqrt{ } c
\end{aligned}
$$

Where $\mathrm{c}=$ number of defects per sample

iii) Interpretations of the control chart results: After plotting, the next step is determining whether the points are statistically controlled or not. Figure 8 and 9 were the appropriate charts designed and implemented for both variable and attribute. The project considered that the process was not statistically controlled if a single point plots outside the control limits or if there was a run of six or more consecutive points, steadily increasing or decreasing. Sometime a point was assumed to be out of control, if nine or more consecutive points fell to one side of the center line. If there was a point out of control, remedial actions were taken to remove special causes and the remaining samples were used to determine the revised center line and control limits for the control chart. In figure 9, we can see that the variable measurement that was taken on April 03, around 11:00 AM and April 04, 2010 around 1:30 PM, was out of the upper limit control line.

f) Remedial action plan design: The remedial action was developed for process improvement by detecting and correcting the special variations. The SPC team was established for proper implementation of the project. The team had the

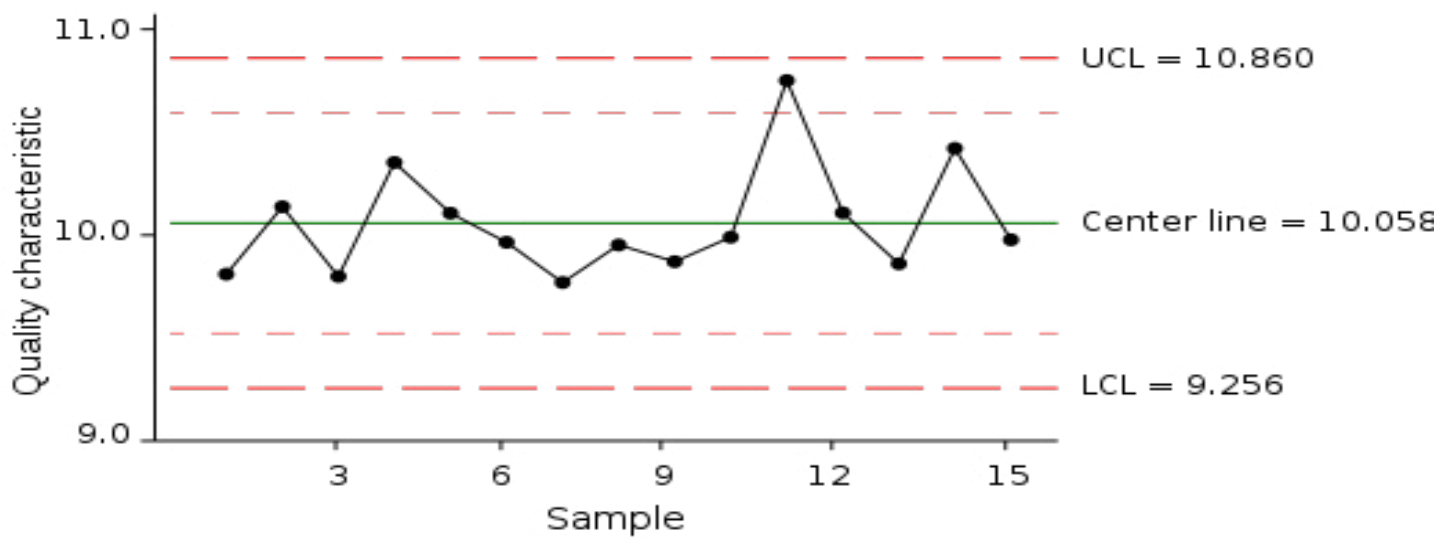

Figure 7. Basic Control Chart component 


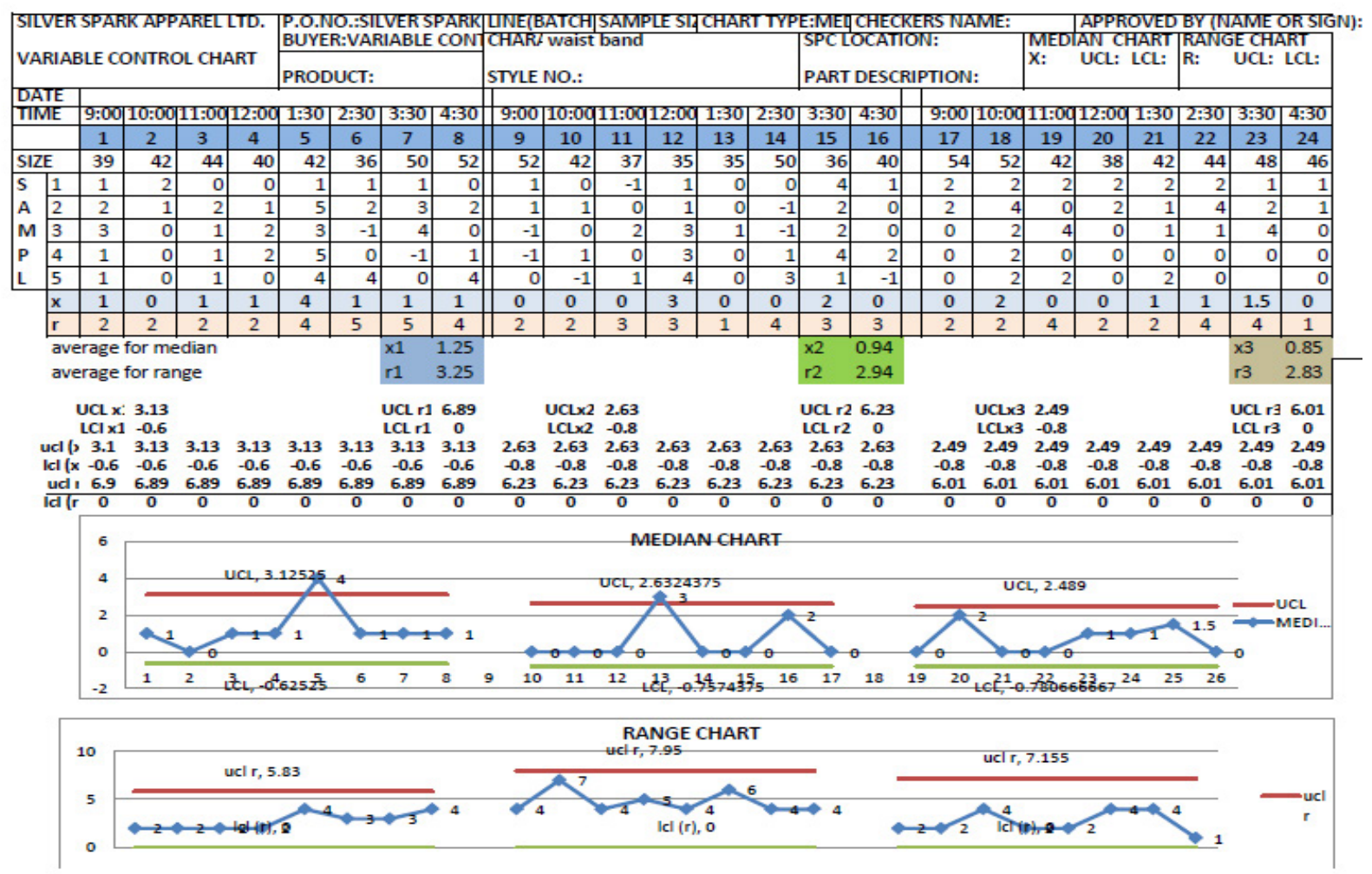

Figure 8. Applied variable control chart

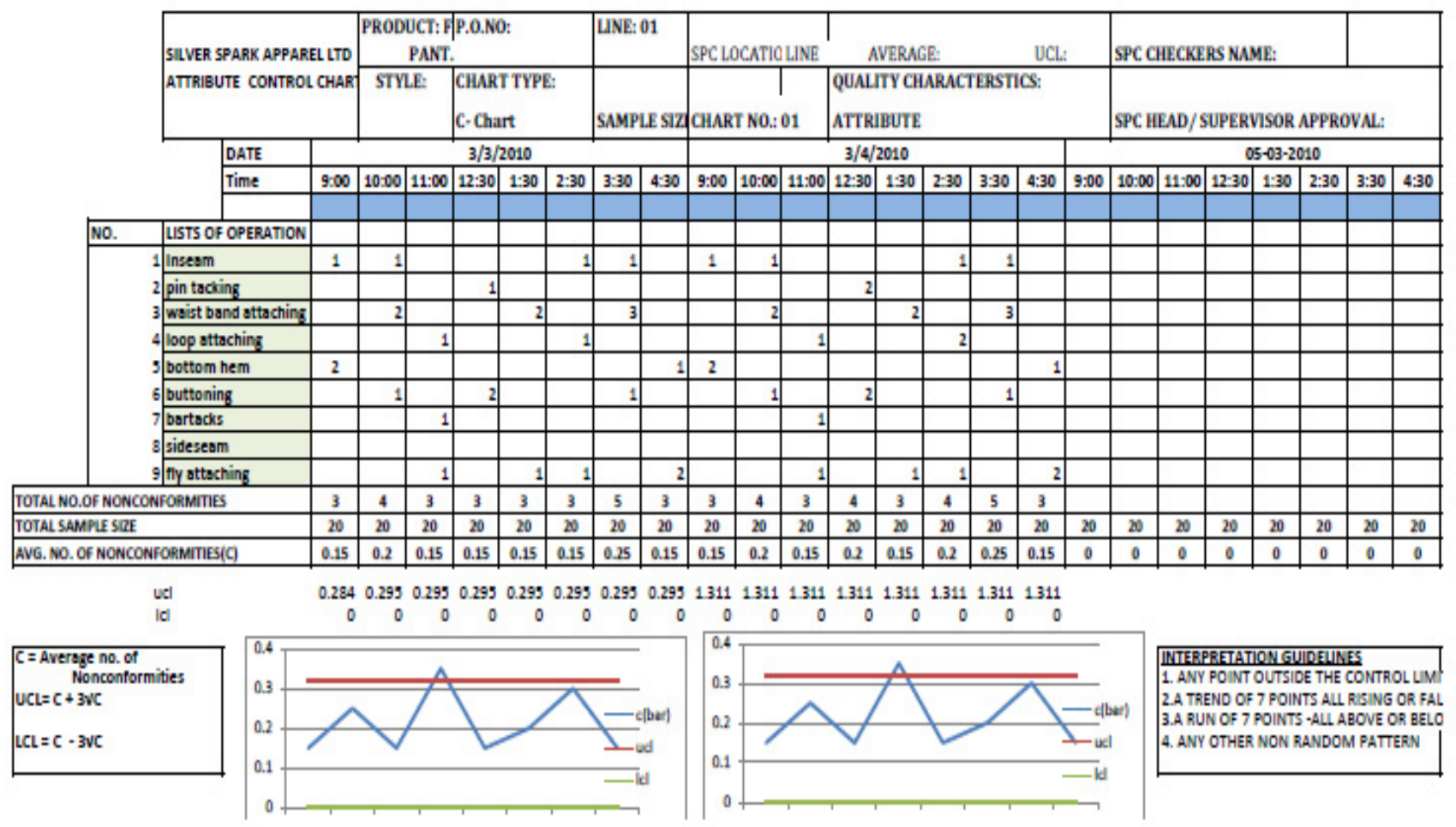

Figure 9. Applied attribute control chart 
concept of SPC and it consisted of the quality manager, assistant production manager, quality controller, production line supervisors, quality team leaders and maintenance section in charge. The established team held a meeting once a month, to evaluate the implemented SPC systems. Based on the action plan (Figure 10), the presence of a point falling outside the standard deviation limits, as seen in Figure 9, was the most widely used if the SPC checkers had to always get their report signed by the quality team leaders. The team leader understood well both SPC and the operations in the lines. If there was a point that made the process out of control, first
SPC checker would go to the particular operation and see what was happening. The problem may have arisen from man, machines, methods and materials. If the problem was manmade, the probable cause was the operator being new or the stitching being done in the wrong way. The SPC checker would correct the problem by being around until the operator rectified the problem. As shown in Figure 11, if the problem was beyond the SPC checker's capacity, then she/he would inform the quality in-charge, and similarly the matter would reach the quality manager, line supervisor, assistant production manager and even higher level. In order to have a permanent solution

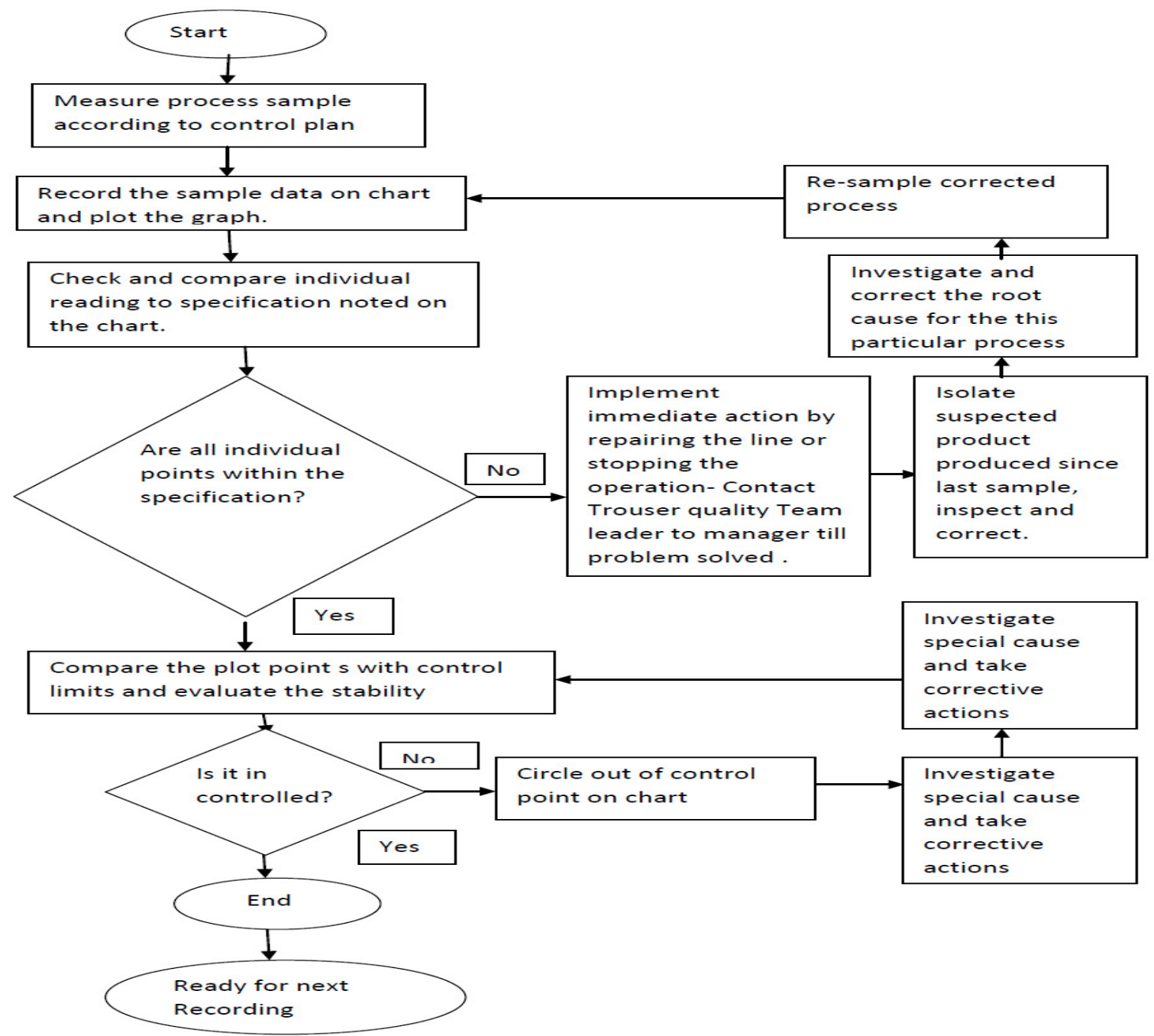

Figure 10. Remedial action plan for process improvement
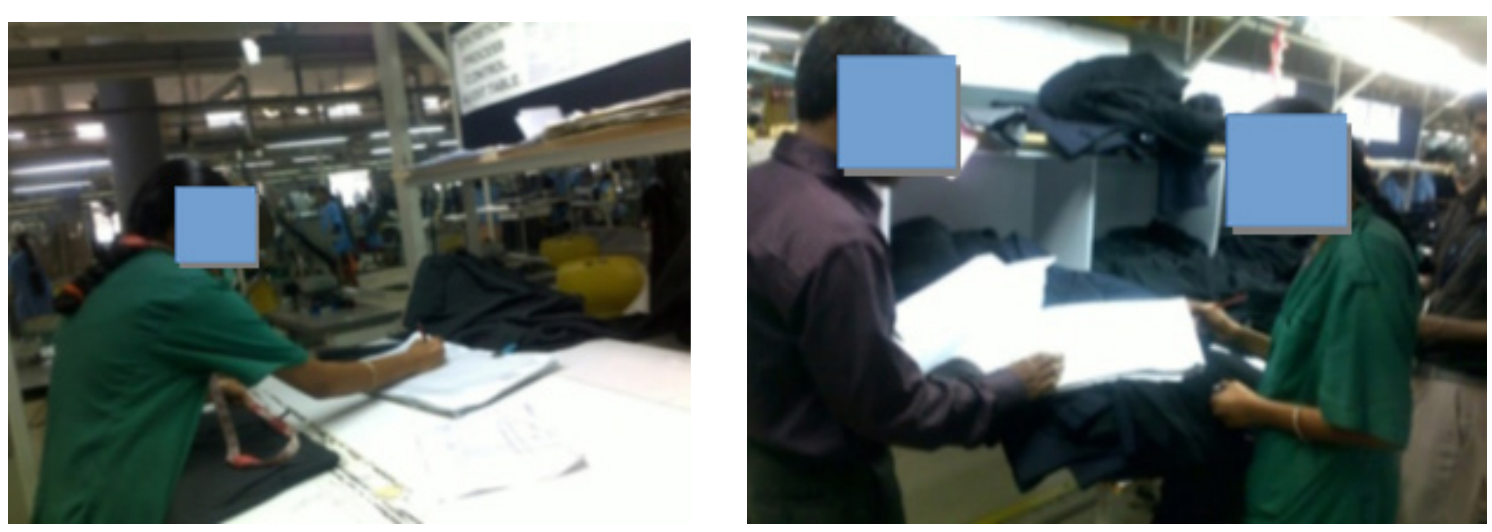

Figure 11. SPC workers plotting \& reporting the chart to quality manager 
for quality/process improvement, there was a need to involve the whole workforce.

g) Training on awareness for workers in SPC concepts and tools: As the famous Quality Guru Dr. Kaoru Ishikawa said "Quality control begins with education and ends with education". Training about the fundamentals of SPC for proper implementation is very important for everyone in the factory ; however, as shown in Table 8 and Figure 12, the training was given in the company for selected and appropriate personnel.

\section{Results and Findings}

Among the seven SPC tool's, control charts were found to be appropriate in controlling the processes due to different advantages such as it provides indications of when to take action, selection of necessary types of remedial action, to take indication of when to leave a process alone, monitoring and controlling the process. Control charts were implemented to understand and improve the performance of manufacturing processes and consistence of final products in more economical ways. X-bar and range control charts for variable and c-chart for attribute quality characteristics were found to be the best for implementation in the sewing lines.

The manual SPC system was also found to be very appropriate systems for selected companies, since this works for companies applying SPC system for the first time and had different faults in the process. The company gained many benefits from the implementation of SPC, such as, general quality awareness being created among the employees, and the training on SPC are knowledge on quality concepts, better understanding of processes, analyzing processes using statistical methods and as a whole, made the employees a part of the quality improvement process.

Figure 13 and 14 showed the data after the implementation of the control charts for the selected critical parameters and the three months' data analysis showed that the implementation of SPC reduced the average alteration rate due to the attribute quality characteristics had been reduced from $9.141 \%$ to $6.4 \%$.

\section{CONCLUSIONS}

The study found that implementation of SPC system is more difficult in garment industries at the initial stage due to the involvement of different bodies in the process. Even though SPC is implemented for the first time, applying and operating simple control charts using the manual SPC system was found to be more appropriate than other systems. Proper training and education of the workers about SPC is one of the major issues that contribute a lot during SPC implementation. The training enhanced the level of knowledge and understanding of workers regarding when, where and how to apply the SPC tools and techniques. Proper and immediate action was found to be most important in the implementation process. Successful implementation of the results of this project can also significantly improve the process performance of other manufacturing units with appropriate modification.

The study recommended that the company should give extra training to the workers regarding SPC to get the proper result and to improve the system. The selection of SPC workers also should be based on interest and on statistical skill for easy understanding and interpretation of the system. In order to see the good result of SPC, the company should give great attention

Table 8. Workers SPC Training Plan

\begin{tabular}{|c|c|}
\hline Audiences: & Supervisors, team leaders, quality checkers and some specific operators \\
\hline Goal: & To introduce process control and tools used, process variation, developing problem solving and teamwork. \\
\hline Contents: & $\begin{array}{l}\text { Different basic quality control tools, control charts with construction and interpretation, basic terms and } \\
\text { definitions (mean, median, range, standard deviation, etc.) }\end{array}$ \\
\hline When: & Before implementation of statistical process control \\
\hline Duration: & Two days of theory followed by on-the-job training for one week \\
\hline Venue: & Presentation and discussion hall of the company \\
\hline
\end{tabular}
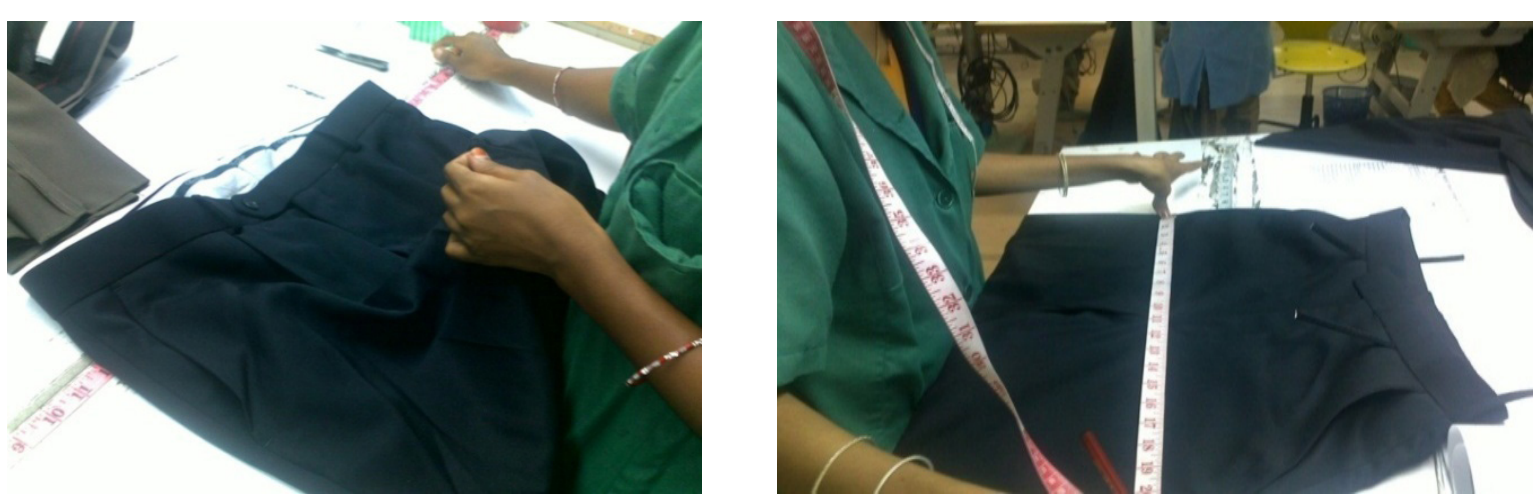

Figure 12. On job training on trouser variable Measurement 


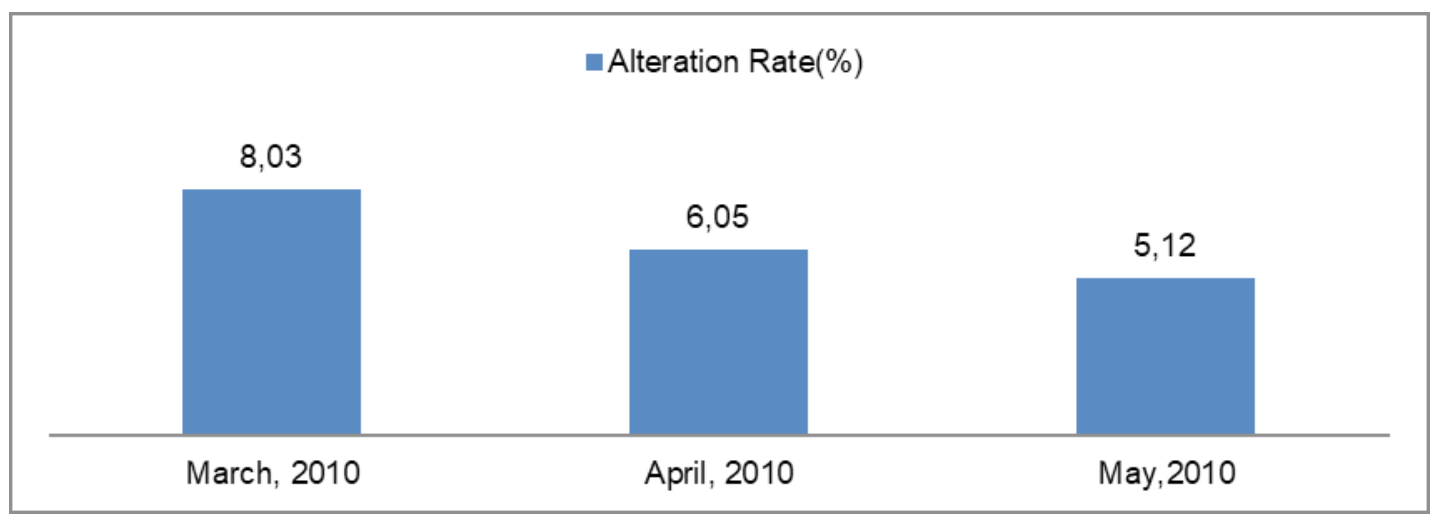

Figure 13. Average alteration rate percentages of the sewing line in four months after implementation

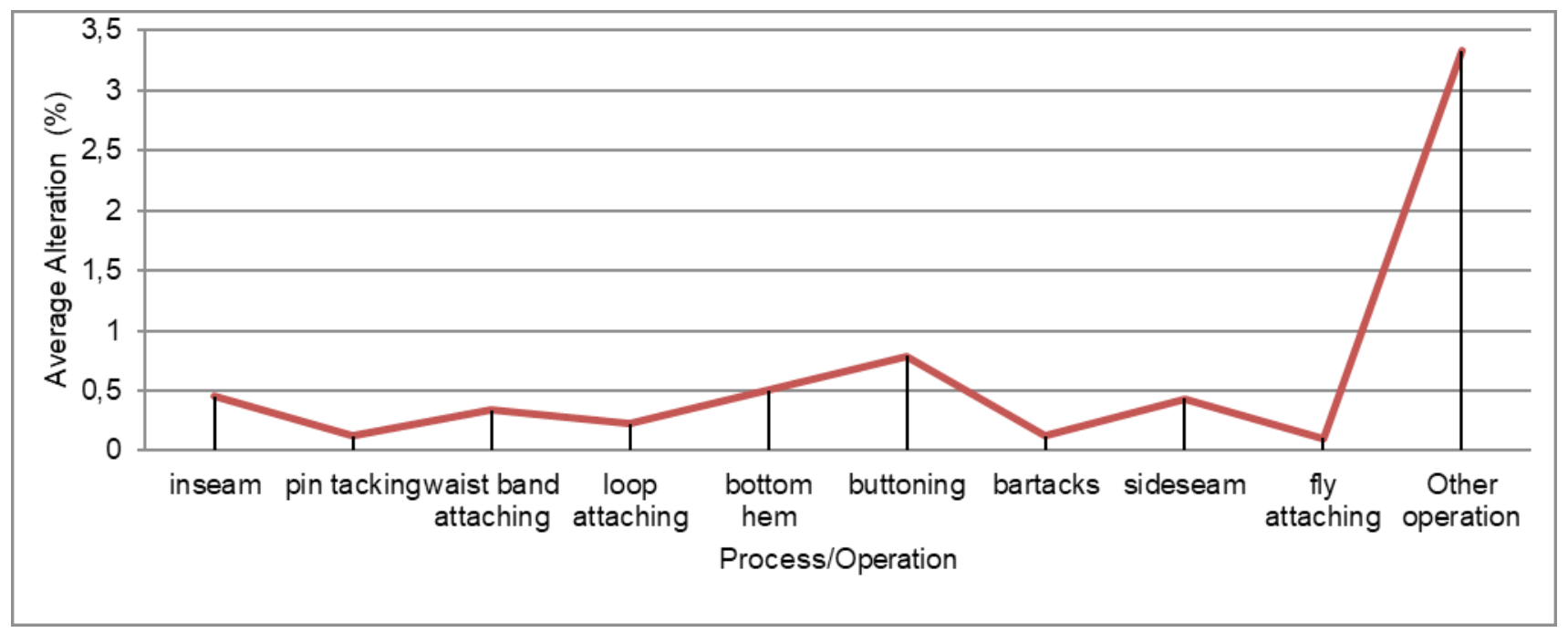

Figure 14. Average alteration rate percentages of the sewing line in three months after implementation

and work with SPC continuously without interruption. The control chart printed sheet also has to be available at every time without any failure for continuous recording of data. The overall implementation of SPC in the line was successful mainly in the identification of the problems; however, improvement has to work on managerial decision for the effectiveness of proper solution for the respective problems. Since the process is tiresome, the main problem or barriers observed in the implementation of SPC system were lack of maintaining commitment and support from management to operators. Lack of awareness towards potential benefits of SPC among the majority of supervisors and workers was challenging during implementation. Inadequate and imprecise measurement system for variable measurement and misinterpretation of control charts at the beginning of the implementation were leading to wrong decision.

\section{RECOMMENDATIONS}

a) Retrain workers regarding SPC in order to improve quality at minimum cost.

b) Selection of workers should be based on interest and statistical skills in order to understand and interpret SPC system easily. c) Continuous work with SPC and full support by the company management will always ensure good results.

d) Control charts should be available at the right place all the times.

e) For effective improvement to be realized, management decision must focus on proper solutions for respective problems.

\section{SUGGESTION FOR FURTHER STUDY}

- Use of SPC software in the implementations of SPC process

- Identification of interrelations between the various processes of manufacture

- Determination of SPC system capability and performance

\section{ACKNOWLEDGMENTS}

The authors would like to "University Research Project of Philosophy and Social Sciences of Jiangsu Province"; to support the financial with serial number of this project: 2017SJB1399. Moreover, we would like to thank NIFT, Bangalore, India and Silver Spark Apparel Limited Company for permitting to work on this project and to use the data files of the company. 


\section{References}

[1] Mason, B. \& Antony, J., Is SPC Just about Control Charts. Unpublished work.

[2] Montgomery, D. C., Introduction to Statistical Quality Control, 6th Edition. New York: John Wiley and Sons, 2009.

[3] Shewhart, W. A, "Statistical Method from the Viewpoint of Quality Control", Washington DC: The Graduate School of the US Department of Agriculture, 1939.

[4] Sultana, F., Islam, N.R., Azeem, A. Implementation of Statistical Process Control (SPC) For Manufacturing Performance Improvement. Journal of Mechanical Engineering, 2009, vol.40 (1), pp.15-21.

[5] Semel, F. J., David, J. K. and Gummeson, P.U., Statistical Process Control in Iron Ponder Production and New Product Development. Presented at the SAE Congress Detroit, Michigan, February 29-March 4, 1998, Hoeganaes Corporation, River Road \& Taylors Lane Riverton, New Jersey.

[6] Fouad, R.H. and Mukattash, A., "Statistical Process Control Tools: A Practical guide for Jordanian Industrial Organizations". Jordan Journal of Mechanical and Industrial Engineering, 2010, vol. 4(6), pp. 693 - 700.

[7] Ab Rahman, M. N., Zain, R.M., Nopiah, Z.M., Jaharah A. G., Baba Md D., Mohamad N. \& Ismail A.R., Statistical Process Control in SMEs. A Case Study. 4th WSEAS/ IASME International Conference on Dynamical Systems and Control (Control'08), 2008, Corfu, Greece, October 26-28.

[8] Ab Rahman M.N. et al., The Implementation of SPC in Malaysian Manufacturing Companies. European Journal of Scientific Research, 2009, 26(3), pp. 453-464.

[9] Finison, L.J., Finison, K.S. and Bliersbach, C.M., The use of control charts to improve healthcare quality. Journal of Healthcare Quality, 1993, Vol. 15 No. 1, pp. 9-23.

[10] Arthur, B., Phillip, K., Jan, D., Richard, N. and Celia, H., "Statistical Inference at Work: Statistical Process Control as an Example". Statistics Education Research Journal, vol. 7(2), pp.130-145, 2008.

[11] Stephanie J. R. and John H. R, "The Use Of Statistical Quality Control Charts In Monitoring Interviewers", University of North Carolina, Chapel Hill, NC 27599, 1999.

[12] Sharaf El-Din M. A., Rashed, H. I. and El-Khabeery M. M., "Statistical Process Control Charts Applied to Steelmaking Quality Improvement”, Quality Technology \& Quantitative Management, vol.3 (4), pp.473-491, 2006.

[13] Omar, M. H., "Statistical Process Control Charts for Measuring and Monitoring Temporal Consistency of Ratings", Journal of Educational Measurement, vol. 47(1), pp.18-35, 2010.
[14] Victor, E. S., Jaideep G. M. and Michael J. S. (1994), "ס Charts for Short Run Statistical Process Control," International Journal of Quality \& Reliability Management, vol.11 (6), pp.50-56.

[15] Brannstorm-Stenberg, A. \& Deleryd, M., "Implementation of Statistical Process Control and Process Capability Studies: Requirements or Free will?" TQM Journal, vol.10, Issue 4-5, 1999.

[16] Kuang-Han, C., Duane, S. B. and Roy E. W., "Multivariate Statistical Process Control and Signature Analysis Using Eigen factor Detection Methods", the 33rd Symposium on the Interface of Computer Science and Statistics, Costa Mesa, CA, June 2001.

[17] Hanna, S. M., "Application of Statistical Process Control (SPC) In the Manufacturing of Medical Accelerators", Proceedings of the 2003 Particle Accelerator Conference, Concord, CA 94520, USA, 2003.

[18] Rai, B.K., "Implementation of statistical process control in an Indian tea packaging company", International Journal of Business Excellence, 1, Nos.1/2, pp. 160-174, 2008.

[19] Anna L. S. and Sohail S. C., "Use of Statistical Process Control in Bus Fleet Maintenance at SEPTA", Journal of Public Transportation, 8(2), 2005.

[20] Rungasamy, S., Antony, J. and Ghosh, S, "Critical success factors for SPC implementation in UK small and medium enterprises: some key findings from a survey", The TQM Magazine, vol. 14(4), pp. 217 - 224, 2002.

[21] Raymond, W. P., "Use of Statistical Process Control (SPC) Versus Traditional Statistical Methods in Personal Care Applications", Presented at the 17th IFSCC International Congress Yokohama October 13-16, Dow Corning Corporation, Midland, MI 48686, USA, 1992.

[22] Mitra, A, Fundamentals of Quality Control and Improvement, Second Edition. New Delhi, India: Pearson Education Inc, 2002.

[23] Wood, M., "Statistical methods for monitoring service process", International Journal of Service Industry Management, Vol. 5 No. 4, pp. 53-68, 1994.

[24] Beamon, B.M. and Ware, T.M., "A process quality model for the analysis, improvement and control of supply chain systems,", International Journal of Physical Distribution \& Logistics Management, Vol. 28 No. 9/10, pp. 704-15, 1998.

[25] Does, R.J.M.M., Roes, K.C.B. and Trip, A., Statistical Process Control in Industry, Kluwer Academic Publishers, Dordrecht, 1999. 